\title{
Editorial
}

\section{Failure Diagnosis and Prognosis of Induction Machines}

\author{
Guy Clerc
}

check for

updates

Citation: Clerc, G. Failure Diagnosis and Prognosis of Induction Machines. Energies 2022, 15, 1483. https:// doi.org/10.3390/en15041483

Received: 15 February 2022 Accepted: 16 February 2022 Published: 17 February 2022

Publisher's Note: MDPI stays neutral with regard to jurisdictional claims in published maps and institutional affiliations.

Copyright: (C) 2022 by the author. Licensee MDPI, Basel, Switzerland. This article is an open access article distributed under the terms and conditions of the Creative Commons Attribution (CC BY) license (https:// creativecommons.org/licenses/by/ $4.0 /)$.
INSA Lyon, Ecole Centrale de Lyon, University Lyon, Université Claude Bernard Lyon 1, Ampère UMR5005, F-69622 Villeurbanne, France; guy.clerc@univ-lyon1.fr

\section{Introduction}

Induction motors have numerous advantages due to their robustness and their powerweight ratio. However, they are also subject to several electrical and mechanical faults. Many methods have been developed to diagnose such failures and prevent unwanted stop. These methods can be based on MCSA, vibrations, electromagnetic noise, electrical or magnetic fields, etc. [1], and applied to different load profiles and dynamics.

Various techniques have been developed, such as the model-based approach and the data-driven approach. The data-driven method deals with signal processing, statistical tools, data mining, and artificial intelligence [2].

Recent trends include an improvement of diagnostic reliability and accuracy [3], and new prognostic techniques [4] have been developed for assessing the remaining useful life of these electrical drives, thereby optimizing maintenance scheduling.

This Special Issue covers the latest research on the characterization of stresses on these machines according to their load profiles, their supervision, the diagnosis of incipient failures of induction machines, the determination of the health state, the prognosis of their remaining useful life at steady state or variable speed, and degraded mode operation. Some papers are extended to the control of asynchronous motors, but the tools developed can be extended to diagnoses such as for new kinds of extended observers and classifiers.

\section{Short Review}

The first paper, "Stray Flux Analysis for the Detection and Severity Categorization of Rotor Failures in Induction Machines Driven by Soft-Starters" [5] deals with diagnosis of rotor faults of asynchronous machine driven by soft starters. It is carried out by the time-frequency analysis of magnetic flux during the starting state and FFT analysis during the steady state. Mixing the transient-based analyses and the steady-state, this method allows both qualitative and quantitative evaluation of rotors faults. It could be extended to other rotating machines.

The second paper, "A Novel Deep Clustering Method and Indicator for Time Series Soft Partitioning" [6] presents a new unsupervised classifier which extracts ageing states from different time series. It is based on image processing and the U-net network. This approach allows the labelling of ageing data, considering the industrial constraints related to both the quality and the amount of data. It introduces a new clustering quality indicator dedicated to ageing time series.

The third paper, "A New Analytical Method for Modelling the Effect of Assembly Errors on a Motor-Gearbox System" [7] proposes a geometric-based method combined with the potential energy approach to model the effect of assembly errors on the time varying mesh stiffness of a mating gear pairs coupled to a motor. It allows the detection of actual contact points during the meshing process. Two types of mounting errors were considered in this study: the center distance error and the eccentricity error. Their impacts are evaluated on the TVMS and the meshed frequency components.

The fourth paper, "Induction Motor PI Observer with Reduced-Order Integrating Unit" [8] presents a proportional integral observer with a reduced integrating unit order to 
reconstruct the magnetic fluxes and the angular speed of an induction motor. It has been applied to field-oriented control. However, this observer could be extended to other types of control such as direct torque control (DTC) or multiscalar control and on model-based diagnosis of either rotor faults or inter turn short circuits.

The fifth paper, "Leveraging Label Information in a Knowledge-Driven Approach for Rolling-Element Bearings Remaining Useful Life Prediction" [9] develops a new approach to predict RUL. A stack of autoencoders connected in series are designed for the integration of labels as a source of knowledge. The authors reinforced data-driven algorithms based on C-LSTM to predict RUL. This work has demonstrated good performance in many tests. Future work will focus on reducing the complexity of the algorithm and improving the labelling process.

The last paper, "Variable Speed Diesel Generators: Performance and Characteristic Comparison" [10] compares the different technologies of variable speed diesel generators in terms of efficiency and reliability. This work is fully relevant within the context of hybridization of renewable energies.

Acknowledgments: I am grateful to the MDPI Publisher for the invitation to act as guest editor of this special issue. I address a special thanks to Florence Li for her continuous support to this work and to the reviewers and authors for their contribution.

Conflicts of Interest: The author declares no conflict of interest.

\section{References}

1. Tang, J.; Yang, Y.; Chen, J.; Qiu, R.; Liu, Z. Characteristics Analysis and Measurement of Inverter-Fed Induction Motors for Stator and Rotor Fault Detection. Energies 2019, 13, 101. [CrossRef]

2. Strangas, E.G.; Clerc, G.; Razik, H.; Soualhi, A. Fault Diagnosis, Prognosis, and Reliability for Electrical Machines and Drives; Wiley: Hoboken, NJ, USA, 2021; 448p, ISBN 978-1-119-72275-5.

3. Kacor, P.; Bernat, P.; Moldrik, P. Utilization of Two Sensors in Offline Diagnosis of Squirrel-Cage Rotors of Asynchronous Motors. Energies 2021, 14, 6573. [CrossRef]

4. Teng, W.; Zhang, X.; Liu, Y.; Kusiak, A.; Ma, Z. Prognosis of the Remaining Useful Life of Bearings in a Wind Turbine Gearbox. Energies 2016, 10, 32. [CrossRef]

5. Biot-Monterde, V.; Navarro-Navarro, Á.; Antonino-Daviu, J.A.; Razik, H. Stray Flux Analysis for the Detection and Severity Categorization of Rotor Failures in Induction Machines Driven by Soft-Starters. Energies 2021, 14, 5757. [CrossRef]

6. Eid, A.; Clerc, G.; Mansouri, B.; Roux, S. A Novel Deep Clustering Method and Indicator for Time Series Soft Partitioning. Energies 2021, 14, 5530. [CrossRef]

7. El Yousfi, B.; Soualhi, A.; Medjaher, K.; Guillet, F. A New Analytical Method for Modeling the Effect of Assembly Errors on a Motor-Gearbox System. Energies 2021, 14, 4993. [CrossRef]

8. Białoń, T.; Niestrój, R.; Michalak, J.; Pasko, M. Induction Motor PI Observer with Reduced-Order Integrating Unit. Energies 2021, 14, 4906. [CrossRef]

9. Berghout, T.; Benbouzid, M.; Mouss, L.-H. Leveraging Label Information in a Knowledge-Driven Approach for Rolling-Element Bearings Remaining Useful Life Prediction. Energies 2021, 14, 2163. [CrossRef]

10. Mobarra, M.; Rezkallah, M.; Ilinca, A. Variable Speed Diesel Generators: Performance and Characteristic Comparison. Energies 2022, 15, 592. [CrossRef] 